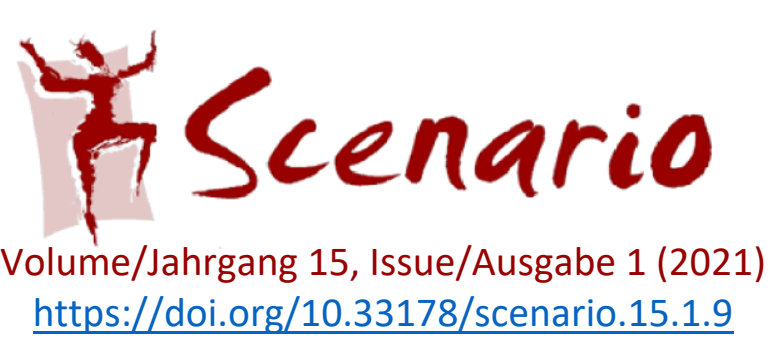

\title{
(No) Drama with Grammar
}

\section{A Case Study of a Performative Approach to Teaching} English Conditional Clauses to Young Adolescent

\section{Learners}

\section{Kristina Hietz}

This Window-of-Practice contribution is based on my Master's thesis written in the Department of Foreign Language Education in Innsbruck, Austria. It discusses a performative approach to teaching grammar in EfL contexts. "Performative" is used as an umbrella term to describe different forms of language teaching that derive from the performing arts (Schewe, 2013). The motivation behind this topic lies in my enthusiasm for drama and the conviction that a dramabased approach applied to language learning is efficient, motivating and sustainable. The contribution provides insights into the methodology and procedure of a case study that investigates effects of drama-based teaching. The case study was performed in 2017 at an upper secondary school in Austria, where English learners were taught English conditional clauses via a drama-based approach. The study, including a control group, a mixed-method, pre-and post-test design, yields quantitative and qualitative data on effects of drama-based teaching. Despite the lack of significant differences in test results between treatment and control groups, the study provides evidence that a performative approach applied to grammar teaching is successful and related to fun, increased motivation and positive group dynamics.

\section{Introduction}

Integrating drama into the foreign language classroom to promote a holistic, social, emotional and action-oriented learning has become more and more recognised and established in the discourse of foreign language teaching, shown by the increasing variety of empirical research (cf. Kaligorou, 2019; Stinson \& Freebody, 2006; Weber, 2017), activity reports, conferences and systematic discussion about an international glossary for the Performative Arts and Pedagogy (see the report by Woodhouse, 2019). Concerning the specific field of teaching grammar, Even (2003) developed a concept that combines grammar instructions and techniques from the performing arts, known as Drama Grammar. In the light of unsatisfactory results of the effects of different ways of grammar instructions, she promotes a postmethod grammar pedagogy that embraces different learning factors and contexts and hence tries to make grammar learning more accessible (Even, 2011). She designs five learning stages for a prototypical drama grammar lesson, in which learners first experience the need for using the grammatical structure, learn its meaning by embedding it into a specific context, understand 
form and function through explicit grammar instruction, apply the form in performative situations and finally reflect on their learning process (Even, 2003, pp. 174-175).

\section{Drama Grammar Lesson Design}

The drama grammar lesson in this study targeted the English conditional clauses and was inspired by Even's approach, but slightly differed to meet the prior knowledge and demands of the specific learner group. For example, some of the five defined learning stages were combined, and an additional drama warm-up phase was included. After the short dramabased warm-up, students engaged in a context-finding phase, where they should come up with a context for three short and separate dialogues, by adding an emotion to the lines that suited the dialogues' situation. The lines were repeated in alternate order by different students. The activity resembled loops, a drama technique "that can be repeated over and over without stopping because the first line of the dialogue can also function as a reaction to the last line" (Dockalova, 2011, p. 28). The three dialogues were the following:
A: "If I see him, I will tell him"
B: "Wait."
A: "If I were you, I would do it."
B: "Ok."
A: "If I had met her, I would have given it to her."
B: "Really?"

The class was divided into three groups, and each group received one of the three different dialogues. Every person was asked to repeat the first line of the dialogue for themselves and think about a context in which this phrase could be said. By doing so, they had to add an emotion in which they wanted to say this phrase, which underlined their imaginary context (the teacher can also assign an emotion to students if needed). One person then took a seat in the middle of the room, all the others facing him/her. Another one approached the person sitting on the chair and said the first line with their chosen emotion. The seated person reacted with a spontaneous emotion or gesture while saying "wait", before getting up and leaving the chair to the person standing, who took this position. This pattern was repeated with the other students and other dialogues. After everyone from group one had taken their turn, one skit chosen by the group was selected and wh-questions (who, what, where, when, why) were discussed. In this short discussion, students augmented the context by adding more information about people involved (who), the situation (what), the place (where), the time (when). This procedure was repeated with the second and third dialogue. After the context- 
finding phase, the grammar was discussed on a meta level, giving input on form and function, before re-entering into another dramatic phase, led by the teacher and expanded by the students.

The next activity used in this study could be positioned between context-finding and dramatic phase. Six volunteers staged three different scenarios, which demonstrated the function of the conditional clauses in context. The students chose one dialogue from the first drama phase and developed scenarios, which should elicit the use of the grammatical structure in question. In this case, it was a young lady, named Lisa, freshly engaged, who eagerly wanted to announce her engagement to her brother at a dinner party, hence using the phrase "If I see him, I will tell him". In the first scene, the brother was at the party, in the second scene, he couldn't be there because he worked in another city, and the third scene was a telephone conversation between Lisa and her reproachful mother, who did not understand why Lisa had not announced the news to her brother. According to the specific scene, the students had to use either the first, second or third conditional clauses. For example for the third scene, Lisa's response to her mother was: "If I had seen him, I would have told him". After the different performances, the dramatic phase was again paused and the students reflected about meaning and form of the conditional clauses. This was done by asking them specific questions about the scenes and the use of the conditional clauses. Examples for such questions are "Why do we use the third conditional in the third scene? " or "what tenses do we use in the ifclause?".

The last drama-based step exclusively focused on the third conditional clause, as this grammatical structure presented the most difficulties. Students had trouble with the form, like using the past perfect tense in the if-clause and would + present perfect tense in the main clause. Thus, the last scene was further explored and extended in another performative activity. The context in this activity was again defined collaboratively, but students could create individual responses. The young couple the students encountered in the second activity went on their honeymoon but everything went wrong. In a telephone conversation, students created a dialogue between Lisa and her mother, who reproached them for not having planned correctly. Responses like "if you had left earlier, you wouldn't have missed the flight", were elicited and embedded into the performances, which were presented in front of the class. The lesson then ended with students reflecting their learning processes.

\section{Research Methodology}

I conducted the case study for two weeks and taught two classes of Austrian 9th grade students. A mixed-method, pretest-posttest design was applied to investigate the effects of drama-based teaching. In fact, scholars stress the necessity of doing more empirical research 
in drama in education, including the use of comparison groups and quantitative measures (Belliveau \& Kim, 2013; Piazzoli, 2011; Weber, 2017). The control group received mainly explicit grammar instructions on English conditional clauses. Input was given through frontal teaching, grammar rules and examples from the course book. Students practiced and applied the grammatical structure in written grammar exercises and one-dimensional verbal practices. The exclusion of any kind of interactive, two-dimensional or performative approach to language was explicitly targeted to avoid any intersection with the drama approach and to clearly distinguish the two learning and teaching methodologies. The drama class, on the other hand, experienced the grammatical phenomenon through a performative approach. Quantitative and qualitative data was collected through a grammar test, which students performed before and after the interventions, external observation reports from the class teachers, a students' questionnaire on drama-based method, and a teacher's journal. The external teachers, observing the teaching and learning processes, received a pre-designed questionnaire, which should direct their attention to three variables: (1) students' performance, (2) teacher's performance, (3) applied methods. The combination of data collection was intended to deliver insights into the learning progress and the effects of dramabased grammar teaching.

Data from the grammar test was analysed statistically via SPSS 23.0 (Statistical Package for Social Science). The coding 0 to 2, with 0 being "wrong", 1 being "semi-correct" and 2 being "correct" was used for analysing the means for the test variables. The data results were checked for normal distribution and analysed with a t-test for dependent samples and a t-test for independent samples. The first one delivered results in mean differences in pre- and posttest scores for both groups. The latter one gave insights into differences between treatment and control groups.

For the questionnaire on drama-based methods, consisting of closed and open questions, a descriptive approach to the data was applied. Closed questions were analysed in frequency tables. Open questions were summarised and classified, following Mayring's (2015) qualitative content analysis. The external observation reports provided additional insight and reflections but were not analysed systematically.

\section{Results and Discussion}

A dependent $t$-test revealed that both groups achieved significantly better results in the posttest, compared to the pretest. Before the interventions, average test scores were 29, after the interventions, they were 39. These scores showed that both types of instructions - dramabased vs. teacher-centred - evoked positive results in test performances (see Fig. 1). 


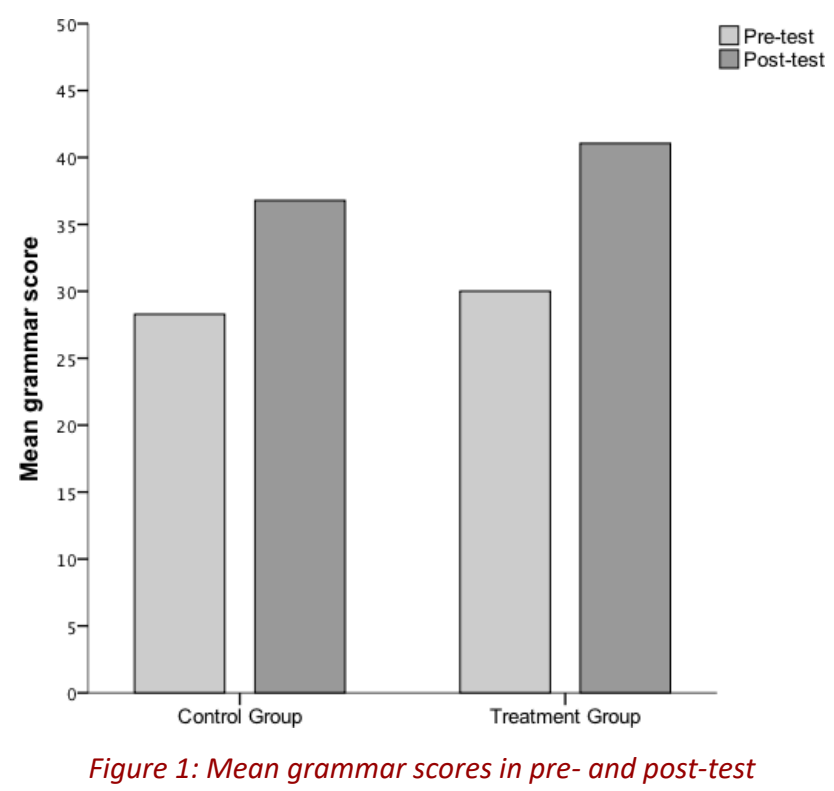

When it comes to comparing the two groups, the independent t-test yielded that there were no significant differences between the groups. There are several reasons for the lack of significant differences between control and treatment groups, such as length of intervention, number of participants, nature of the survey, applied methods and the complexity of second and foreign language acquisition. In fact, Purpura (2004, p. 30) attributes the failure of proving the superiority of one teaching method over another to the complex nature of second language acquisition.

Apart from test scores, the questionnaire and external observation reports revealed that the drama grammar approach was perceived very positively and made grammar learning accessible and efficient. For example, students' feedback yielded that the majority felt learning via a performative approach was fun, with 8 out of 17 students strongly agreeing and 6 agreeing. Furthermore, they felt that drama helped to improve their self-confidence and to understand the topic better. The following two student reactions exemplify this: "Man kann es sich besser merken als wenn man es nur ein mal aufschreibt" ["It's easier to remember than if you just write it down once"], "Man versteht ein neues Thema leichter" ["It is easier to understand a new topic"]. These statements substantiate Even's claim that "drama grammar advances the understanding of grammatical phenomena through concrete and practical application in dramatic situations" (Even, 2011, p. 308).

Furthermore, qualities concerning group dynamics, creativity and self-confidence were generally rated very positively. The vast majority agreed that drama activities support these qualities. 
Drama activities support...

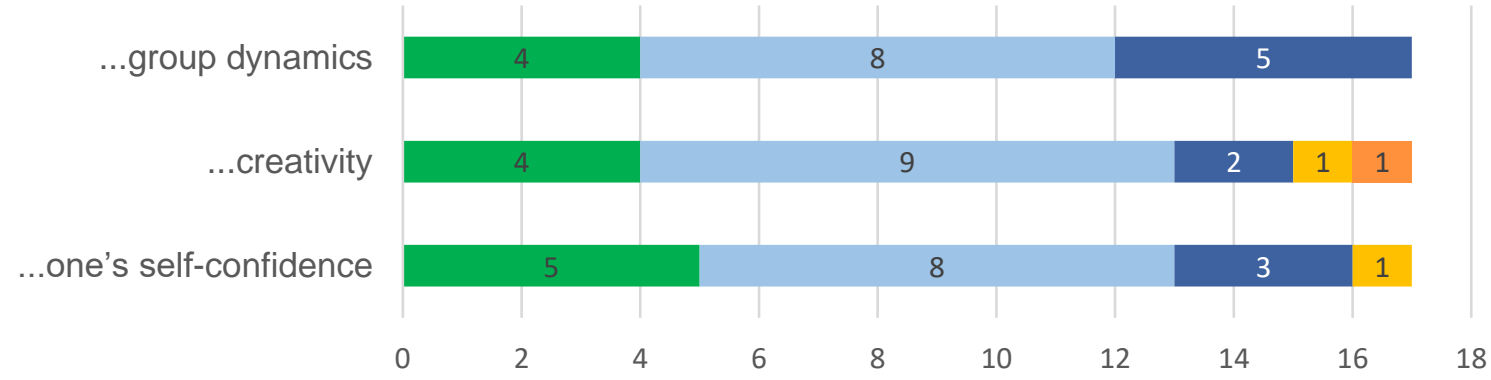

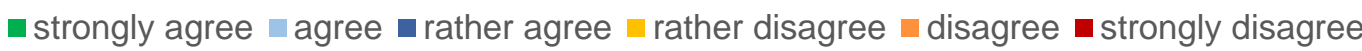

Figure 2: Personal evaluation of drama activities

Next to pre-given answers concerning drama activities, participants were asked if they perceived any personal advantages of drama-based teaching and learning for themselves. 13 out of 17 answered with yes, additionally underlining their response with the following statements:

\begin{tabular}{l|l} 
Advantages & Number \\
\hline it's fun & 4 \\
it improves one's self-confidence & 4 \\
it improves pronunciation & 2 \\
you remember things better & 2 \\
you understand grammar better & 2 \\
it improves speaking skills & 1 \\
it improves listening skills & 1 \\
it improves creativity & 1 \\
it's easier than learning by heart & 1 \\
you learn to speak in front of the class & 1 \\
you learn to speak with emotions & 1 \\
Table 1: Statements on personal advantages of drama-based teaching
\end{tabular}

The external observers of both drama lessons and the comparison lessons provided additional feedback on pupils' interaction, the teacher's performance and applied activities. The teacher who accompanied the drama lessons observed differences between the first and the second lesson. She remarked that in the first lesson, pupils' motivation was relatively low, which she mainly ascribed to the late hour of the day. Furthermore, she described them as shy as they were novices to drama activities. During the second lesson, however, the external teacher observed an increased engagement and participation in the use of the English language and a dynamic atmosphere. 
In regard of these positive responses, drama-based teaching receives its legitimate and valued position in foreign grammar teaching. In fact, 11 out of 17 participants felt that drama activities should be applied more often in their language class.

\section{Limitations and Challenges}

The case study conducted proved positive results of teaching grammar via a performative approach but failed to make well-informed conclusions on the long-term effects. To gain insight into the retention rate, a delayed posttest would have been necessary. Furthermore, the time-consuming aspect of drama activities and the complexity of explanations and performances were regarded as challenges. In this context it is noteworthy that as a novice to drama-based teaching I encountered some difficulties along the way, and the students experienced a drama-based class for the first time. Hence the students tended to be shy initially and were hesitant to step forward and speak dialogue lines in front of their peers in different emotions. More initial icebreakers and group exercises would have positively supported the group dynamics and better prepared them for the drama activities that followed. In that respect, more time and experience could have facilitated the performative processes (Borge, 2007; Schewe, 1993). Hence, preparing teachers and students for using performative approaches in their classroom, for example by implementing drama pedagogy in teacher education, becomes more important (Göksel, 2019; Haack, 2010; Hatzer et al., 2019).

\section{Conclusion}

Regarding my personal drama-based teaching, time and experience have helped me to use performative approaches meaningfully in the classroom. While the study of relevant theoretical sources has been important it is especially through the active work with kids that I have found out what works well with a particular group of students and what does not work so well. For example in my role as a language assistant I coordinated a German drama lunch club and through the experimentation with different drama techniques and groups expanded my awareness of drama-based teaching. Currently I work as an English teacher in a lower secondary school in Austria and regularly incorporate small-scale drama forms in the classroom. This varies from communication activities, single drama exercises (Freeze-Frame, Opinion Lines, Red-Socks Pattern, Kotzendes Känguru, etc.) to (role) plays or improvisations. While try and error is still part of this process the more time and experience we have with drama in the classroom the more we profit from this beautiful way of teaching a language. 
Hietz: (No) Drama with Grammar

Bibliography

Belliveau, G., \& Kim, W. (2013). Drama in L2 learning: A research synthesis. Scenario, 7(2), 7-27. https://doi.org/10.33178/scenario.7.2.2

Borge, S. (2007). The use of drama activities in teaching German in a third-level classroom. Scenario, 1(1), 1-24. https://doi.org/10.33178/scenario.1.1.1

Dockalova, B. (2011). Loops: A multi-purpose drama technique for the language classroom. Scenario, 5(1), 28-36. https://doi.org/10.33178/scenario.5.1.6

Even, S. (2003). Drama Grammatik. iudicium.

Even, S. (2011). Drama grammar: Towards a performative postmethod pedagogy. The Language Learning Journal, 39(3), 299-312. https://doi.org/10.1080/09571736.2010.543287

Göksel, E. (2019). Performative professionalisation in the context of teacher training: First experiments with the use of drama-based pedagogies across the curriculum. Scenario, 13(1), 91-94. https://doi.org/10.33178/scenario.13.1.6

Haack, A. (2010). KünstlerInnen der improvisierten Aufführung. Scenario, 4(1), 35-53. https://doi.org/10.33178/scenario.4.1.4

Hatzer, U., Höfferer, D., Köhler, J., Roth, S., \& Wrentschur, M. (2019). Performing arts \& pedagogy: An Austrian perspective. Scenario, 13(2), 44-58. https://doi.org/10.33178/scenario.13.2.4

Kalogirou, K. (2016). Step into drama and teach English affordably. Scenario, 10(1), 33-48. https://doi.org/10.33178/scenario.10.1.3

Mayring, P. (2015). Qualitative Inhaltsanalyse: Grundlagen und Techniken. Beltz GmbH, Julius.

Piazzoli, E. (2011). Process drama: the use of affective space to reduce language anxiety in the additional language learning classroom. Research in Drama Education: The Journal of Applied Theatre and Performance, 16(4), 557-573. https://doi.org/10.1080/13569783.2011.617104

Purpura, J. E. (2004). Assessing grammar (Cambridge Language Assessment). Cambridge University Press.

Schewe, M. (1993). Fremdsprache inszenieren: Zur Fundierung einer dramapädagogischen Lehr- und Lernpraxis. Zentrum für pädagogische Berufspraxis. https://cora.ucc.ie/handle/10468/561

Schewe, M. (2013). Taking stock and looking ahead: Drama pedagogy as a gateway to a performative teaching and learning culture. Scenario, 7(1), 5-27. https://doi.org/10.33178/scenario.7.1.2

Stinson, M., \& Freebody, K. (2006). The Dol Project: The contributions of process drama to improved results in English oral communication. Youth Theatre Journal, 20(1), 27-41. https://doi.org/10.1080/08929092.2006.10012585

Weber, S. (2017). Drama pedagogy in intermediate German: Effects on anxiety. German as a Foreign Language (GFL), 1, 1-21.

Woodhouse, F. (2019). The performative arts and pedagogy project - Towards the development of an international glossary. Scenario, 13(1), 99-105. https://doi.org/10.33178/scenario.13.1.8 